\title{
Scientific Exploration of Induced SeisMicity and Stress (SEISMS)
}

\author{
Heather M. Savage ${ }^{1}$, James D. Kirkpatrick ${ }^{2}$, James J. Mori ${ }^{3}$, Emily E. Brodsky ${ }^{4}$, William L. Ellsworth ${ }^{5}$, \\ Brett M. Carpenter ${ }^{6}$, Xiaowei Chen ${ }^{6}$, Frédéric Cappa ${ }^{7}$, and Yasuyuki Kano ${ }^{3}$ \\ ${ }^{1}$ Lamont-Doherty Earth Observatory, Columbia University, Palisades, NY, USA \\ ${ }^{2}$ Department of Earth and Planetary Sciences, McGill University, \\ 3450 University St., Montréal, QC H3A 0E8, Canada \\ ${ }^{3}$ Disaster Prevention Research Institute, Kyoto University, Kyoto, Japan \\ ${ }^{4}$ Department of Earth and Planetary Sciences, University of California-Santa Cruz, \\ Santa Cruz, California 95064, USA \\ ${ }^{5}$ Department of Geophysics, Stanford University, 397 Panama Mall, Stanford, California 94305-2215, USA \\ ${ }^{6}$ School of Geology and Geophysics, University of Oklahoma, Norman, USA \\ ${ }^{7}$ CNRS, OCA, IRD, Géoazur, Sophia Antipolis, France
}

Correspondence to: Heather M. Savage (hsavage@ldeo.columbia.edu)

Received: 18 August 2017 - Revised: 30 October 2017 - Accepted: 3 November 2017 - Published: 30 November 2017

\begin{abstract}
Several major fault-drilling projects have captured the interseismic and postseismic periods of earthquakes. However, near-field observations of faults immediately before and during an earthquake remain elusive due to the unpredictable nature of seismicity. The Scientific Exploration of Induced SeisMicity and Stress (SEISMS) workshop met in March 2017 to discuss the value of a drilling experiment where a fault is instrumented in advance of an earthquake induced through controlled fluid injection. The workshop participants articulated three key issues that could most effectively be addressed by such an experiment: (1) predictive understanding of the propensity for seismicity in reaction to human forcing, (2) identification of earthquake nucleation processes, and (3) constraints on the factors controlling earthquake size. A systematic review of previous injection experiments exposed important observational gaps in all of these areas. The participants discussed the instrumentation and technological needs as well as faults and tectonic areas that are feasible from both a societal and scientific standpoint.
\end{abstract}

\section{Introduction}

Understanding how earthquakes nucleate, propagate, and arrest is one of the major outstanding challenges in Earth science. The difficulty with making progress on this challenge stems from our inability to directly observe faults deep in the Earth where earthquakes nucleate, as well as our inability to test existing theory at the field scale, where we expect complex feedbacks between stress, pore pressure, and slip. These parameters could be measured by borehole and surface-based instruments during an earthquake if they were deployed near the rupture source. Previous fault zone drilling projects have probed the earthquake source soon after large events (e.g., following the 1995 Kobe, 1999 Chi Chi, 2008 Wenchuan, and 2011 Tohoku earthquakes), and have enabled estimations of important parameters like stress during the earthquake (Ikeda, 2001; Ma et al., 2006; Fulton et al., 2013; Li et al., 2013). However, capturing the dynamics of an earthquake can only be achieved by instrumenting a fault prior to failure and monitoring it before, during, and after slip. Because earthquakes cannot be predicted, planning for a near-source deployment is extremely challenging. One possible method to ensure success is to induce failure through controlled fluid injection, similar to earthquakes induced by wastewater injection and recent small-scale (i.e., within meters of a fault zone), controlled experiments (e.g., Guglielmi et al., 2015). 
Installing instruments inside the fault through fault zone drilling is the only way to obtain the small signals deep in the Earth necessary to investigate earthquake physics. An earthquake induced on a known fault through targeted fluid injection would provide an opportunity to obtain near-field information with a dense network of instruments deployed prior to the experiment. The fault could be fully characterized before the experiment with active source seismology, borehole geophysics, surface geology, and core-based investigations. An observatory of boreholes containing strain, pore pressure, temperature sensors and down-hole seismometers constructed in advance of the experiment would collect real-time data over a large frequency band (i.e., $\mathrm{mHz}$ to $\mathrm{kHz}$ ) close to the source from initiation to arrest.

The recent escalation in induced earthquakes in North America makes an investigation like this a community priority. By defining the conditions necessary to induce an earthquake, the results would demonstrate how to prevent unintentionally induced earthquakes. A project of this scope requires significant community discussion and buy-in before going forward. The Scientific Exploration of Induced SeisMicity and Stress (SEISMS) workshop was a first step in this direction. The overall goal of the workshop was to define the most significant scientific questions that could be addressed by in situ measurements of an earthquake with borehole observatories. In addition, we discussed technological, logistical, and societal hurdles, as well as how to overcome them. The outcome of this workshop includes focused understanding of the unanswered questions in earthquake and fault mechanics, as well as which questions could be addressed through fault zone drilling. Here, we outline the current state of understanding of earthquake physics, as articulated at the workshop, and provide a roadmap of questions that could be addressed through future fault zone drilling.

\section{SEISMS meeting}

\subsection{Itinerary}

The SEISMS workshop was held at Lamont-Doherty Earth Observatory, New York, USA, over 3 days from 29 to 31 March 2017. Attended by 86 participants from 10 countries, including representatives from industry, academia, and education, the workshop was sponsored by the International Continental Scientific Drilling Program (ICDP), the United States Geological Survey (USGS), and the Southern California Earthquake Center (SCEC). The workshop included a series of keynote talks from experts in earthquake physics, borehole instrumentation and observatories, induced earthquakes, and active earthquake experiments (Table 1), as well as group discussions concerning the need for an earthquake experiment, the scientific value of such an experiment, and the potential risks associated with inducing earthquakes.

\subsection{Knowledge gaps between earthquake theory and observation}

The primary goal of the SEISMS workshop was to outline and prioritize critical unresolved questions in earthquake physics. The majority of these questions are centered on our current inability to scale theory based on laboratory experiments to natural faults, as well as our inability to incorporate real-world complexity into lab experiments and models.

Much of our understanding of earthquake nucleation is based on the rate-and-state friction laws, which predict that an earthquake will begin by slipping aseismically until the rupture reaches a critical size, $h^{*}$ :

$h^{*} \sim \frac{\mu L}{(b-a)(\sigma-p)}$,

where $\mu$ is rock shear modulus, $L$ is the critical slip distance, $\sigma$ is normal stress, $p$ is pore pressure, and $a$ and $b$ are rateand-state parameters (Rice, 1993; Scholz, 1998; Ampuero and Rubin, 2008). Because we do not know how some parameters, such as $L$, scale from laboratory to natural fault, the nucleation patch size is unknown, but might range in size from 0.1 to $10 \mathrm{~m}$ and will vary significantly depending on the effective stress resolved along the fault. It is unknown at this point whether the final earthquake size is a function of $h^{*}$. If it was, this would indicate that there is a fundamental difference between small and large earthquakes, as has been suggested when estimating other earthquake parameters such as fracture energy (Viesca and Garagash, 2015). Measurements of the nucleation length scale, accelerations, or moment release during the initial stages of slip are needed to understand the growth of earthquakes. In order to capture these signals, instrumentation would need to be essentially within meters of the slip surface. Such observations could never be made from the surface.

In addition to earthquake initiation, the processes or conditions that cause earthquakes to either arrest or propagate to larger magnitudes remain unknown, which is primarily why earthquake magnitude cannot be predicted. Structural complexity is an aspect of faults whose effects on earthquake dynamics are unknown. Geometric complexities such as nonplanarity have been invoked to serve as nucleation sites (asperities) as well as boundaries to rupture propagation. Fault complexity also affects the slip during an earthquake, efficiency of energy dissipation mechanisms, and the radiation of seismic energy (Dunham et al., 2011). Furthermore, hydraulic diffusivity changes within both the fault core as well as damage zones may have significant control on pore pressure gradients throughout the rupture, and may aid in rupture arrest and the promotion of slow aseismic slip rather than fast seismic slip. In addition to geometric complexity, the controls of materials properties on different regions of the fault, such as regions of preseismic, coseismic, and afterslip, may not be constant through time or along strikes. 
Table 1. SEISMS keynote talks.

\begin{tabular}{ll}
\hline Title & Speaker \\
\hline Topic: Central Questions in Earthquake Physics & \\
\hline The Knowns and Unknowns of Earthquake Physics & Eric Dunham \\
Lessons From Rangely & Barry Raleigh \\
Current Understanding of Induced Seismicity: Surface Observations & Elizabeth Cochran \\
Current Understanding of Induced Seismicity: Theory and Observations at Depth & Mark Zoback \\
\hline Topic: Fault Zone Drilling and Instrumented Boreholes & \\
\hline Fault Zone Drilling Experiences & Stephen Hickman \\
Borehole Observatories & Patrick Fulton \\
\hline Topic: Drilling/Instrumentation Capabilities and Needs & \\
\hline Downhole Logging Tools & Douglas Schmitt \\
In-Situ Experiments & Yves Guglielmi \\
\hline Topic: What Would Make an Ideal Drilling Site? & \\
\hline Oklahoma, USA & Brett Carpenter \\
British Columbia, Canada & David Eaton \\
Basin and Range, USA & Steven Wesnousky \\
Oceanic Transforms & Jeffrey McGuire and James Mori \\
\hline
\end{tabular}

\subsection{Small- to large-scale in situ experiments and the accidental experiment of induced seismicity}

Planning for the SEISMS experiment will lean heavily on the lessons learned from the Rangely experiment conducted during the 1970s (Raleigh et al., 1976). At Rangely, in situ stress measurements and measurement of the frictional strength of the faults led to successful prediction of the pore pressure needed to induce earthquakes, thereby supporting the use of the effective stress law to the scale of earthquakes and faulting. However, not all aspects of the experiment were well explained, for example, the occurrence of earthquakes far from the target fault, which required extreme hydraulic parameters using the conventional explanation. Modern thinking about elastic stresses could potentially solve these problems; however, the lack of geodetic data for the original experiment prevents a detailed analysis. Rangley also demonstrated that a well-characterized site, including tens to hundreds of observation wells, is an imperative. This included the analysis of the size of faults within the field area and minimized the risk of triggering a large earthquake. Armed with new technology in fault zone drilling and geodesy, a new-generation earthquake experiment could more directly measure fault slip and fluid pressures within both the fault core as well as the surrounding damage zone, which should enhance our ability to determine where and when failure will occur.

Recent borehole experiments have successfully induced small earthquakes $\left(-4.5<M_{\mathrm{w}}<-3\right)$ in a controlled way (Derode et al., 2015; Guglielmi et al., 2015; De Barros et al., 2016). Observations of the induced earthquakes have demonstrated that the physical processes that lead to runaway slip are complex and depend on the hydromechanical and frictional characteristics of both the fault and the surrounding rock. These experiments show that a small amount of dilatant aseismic slip can occur before seismic slip, and that earthquakes can be generated even in velocity strengthening material, which laboratory experiments suggested was unlikely (Guglielmi et al., 2015). Furthermore, several current microseismic experiments in underground mines are providing insights into the complexity in small earthquake nucleation (e.g., Yabe et al., 2015). Despite the exciting results of these studies, the earthquakes generated were limited to a small number of small magnitude events. Any change in physics from small to large earthquakes could not be captured in these experiments, and the effects of cumulative wastewater injection remain unconstrained.

Finally, the recent surge of earthquakes associated with hydrocarbon production and wastewater disposal offers new lessons. The frequency of earthquakes occurring in seismically quiet areas such as the Midwestern US and western Canada is greater than has ever been previously recorded (Ellsworth, 2013), and even moderately sized earthquakes could prove hazardous in areas that are unprepared for seismic activity. Many of the recent earthquakes are induced by human activity, but although we know that fluid injection causes induced seismicity (Raleigh et al., 1976), we cannot predict exactly when and where a particular earthquake will occur - just as with tectonic earthquakes. The scientific community should be able to contribute to this problem by defining the stress and fluid pressure conditions that are necessary to cause earthquake slip, but the measurements necessary to make these predictions do not exist. Talks and discussions on 
induced seismicity at the SEISMS workshop mostly focused on the role of inherited structures and stress field characteristics in making an area more inclined to have induced seismicity. Some of the questions included the following. Are stress drops low in induced events (Sumy et al., 2017) or no different than tectonic earthquakes (e.g., Huang et al., 2017; Clerc et al., 2016)? What are pre-stress conditions on the fault within its seismic cycle, and how do they affect induced events? What role do fault damage zones play in communicating fluid pressures over large distances (Hennings et al., 2012)? What metrics are there for tracking how close a fault might be to failure during fluid injection?

\subsection{Necessary components for an "active" earthquake experiment}

\subsubsection{Essential instrumentation}

Recent fault zone drilling and other drilling projects have resulted in significant advances in borehole observatories and drilling capabilities. For instance, borehole instruments routinely include seismometers, thermistors, pore pressure sensors, and strain meters (Fulton et al., 2013; Chiaraluce et al., 2014). Increasingly, fiber optic cables are being emplaced within borehole casing and utilized as seismometers (Constantinou et al., 2016), strain meters and pressure meters (Cappa et al., 2006). To capture length scales appropriate for both the rupture tip region and fault slip patch dimension, observatory coverage across a wide range of scales will likely be required, so this type of instrumentation would be ideal for an active earthquake experiment. Finally, borehole observatories that exist on longer timescales (months-years) will need to carefully consider temperature and fluids at depth, including precursory monitoring.

\subsubsection{Feasible sites}

Preliminary site discussion at the SEISMS meeting focused on what would make a site feasible from both a scientific and safety standpoint. As a group, a list of criteria was developed that would be necessary for a successful site, including

1. faults that are well oriented in the current day stress field and possible to activate;

2. detailed subsurface characterization, including 3-D seismic imaging, determination of the stress and pore pressure fields, combined with surficial geologic mapping;

3. an area with low population density yet developed infrastructure (such as an oil field);

4. pre-existing and ongoing site monitoring; and

5. potential for collaboration from industry to take advantage of existing infrastructure and develop science priorities that can meaningfully contribute to hazard mitigation.
The specific sites discussed included places where induced seismicity is already occurring, like Oklahoma and British Columbia, as well as the Basin and Range, USA, and oceanic transform faults. Both terrestrial and oceanic sites were viewed favorably for an earthquake experiment (Fig. 1). Active experiments on the ocean transforms where frequent repeating events occur (McGuire et al., 2005), and continental faults where events occur much less frequently, can address different aspects of the initiation and rupture process. Also, logistical and observational constraints are very different for the two types of settings. Since there are different advantages and disadvantages for these two types of experiments, there were recommendations that proposals for both types of experiments should be worked on in parallel. Although discussion was not focused on a specific site at this time, the importance of picking a site where detailed understanding of fault structure, including the role of the damage zone in transmission of fluid pressures, number and thickness of localized slip zones, as well as friction strength, could be established before the active phase of the experiment.

\subsection{Societal concerns}

Safety and societal issues regarding potential induced earthquake experiments in various regions were prominent discussion topics throughout the workshop. The concept for the project would be to induce earthquakes through fluid injection, which would represent a hazardous outcome. However, there was recognition that understanding the causes of the many current human-induced earthquakes is an important issue for scientists to undertake. Given the largely unmonitored and uncontrolled way in which earthquakes are being induced in some regions, an experiment such as this would provide a valuable opportunity for the scientific community to provide some constraint on how to limit unintentionally induced seismicity.

Past examples of active geologic experiments show that communication with local officials and the public will be central to a successful project, as well as evaluation of safety risks, which would be essential for any project that might produce felt earthquakes. Outreach and education efforts will be important for any active experiment because this will likely be a high-profile project in the public eye. This should be viewed as an opportunity to provide information about earthquakes and seismic hazards. Plans for outreach activities should be started along with development of science objectives, for example by engaging local members of the public to invest in the project by helping to articulate which questions should be answered with the experiment.

\section{Workshop outcomes and future directions}

Participants identified three key questions at the workshop that should be targeted by the SEISMS project. They all depend on the measurement of stress, deformation, and pore 
(a)

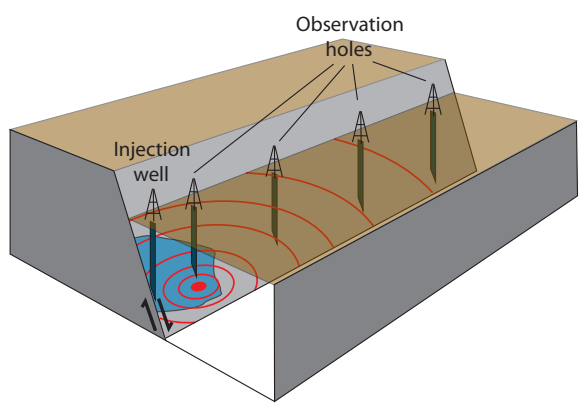

(b)

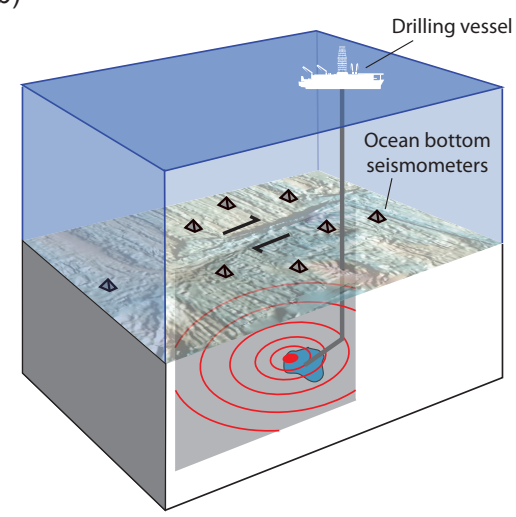

Figure 1. Potential target faults. (a) Continental fault observatory. Fluids pumped at the injection well will trigger an earthquake that can be recorded with seismometers, temperature sensors, strain meters, etc., at the observation holes. (b) Oceanic transform fault observatory. Fluid injected from a ship would trigger an earthquake on the fault that would be recorded by a network of ocean bottom seismometers (OBS in grey pyramids). Observation holes may also be drilled in advance of the injection.

pressure in the ultra-near field of an earthquake, and which therefore require a borehole observatory positioned close to the earthquake source.

\subsection{Can we accurately determine when and where an earthquake is going to occur once fluid pressure is elevated?}

Many induced earthquakes are associated with wastewater injection or hydraulic fracturing operations, both of which elevate fluid pressure and reduce the effective stresses at depth, promoting earthquake occurrence. However, many injection wells do not appear to induce seismicity (e.g., Cornet, 2016; Rivet et al., 2016), some wells appear to induce earthquakes at significant distances from the injector (e.g., Yeck et al., 2016; Goebel et al., 2017; Keranen et al., 2014), and some wells that directly penetrate faults have little effect on stability (Hauksson et al., 2015). These results show that even though the Rangely experiment in the 1970s seemed to demonstrate that the effective stress hypothesis describes fault failure under in situ conditions, it is still currently impossible to predict where and when an earthquake will occur, even within regions where fluid injection is taking place. This is partly because the mechanisms by which stress and pore pressure are transmitted to a fault are poorly understood. Direct fluid pressure increase and elastic stress perturbation have both been shown to be important for triggering earthquakes (e.g., Deng et al., 2016; Segall and Lu, 2015; Barbour et al., 2017), but which is more efficient, and therefore potentially more hazardous, is unknown. Induced earthquakes that occur far from an injection well indicate that fluid pressures are transmitted rapidly, highlighting the importance of complex fault zone hydrogeological structures. Furthermore, there is currently no consensus on how to predict what magnitude of earthquake could arise given a known stress or pore pressure perturbation to a fault (e.g., McGarr, 2014; van der Elst et al., 2016). An experiment to test the response of a fault to a controlled perturbation affecting a known volume in the subsurface could elucidate the conditions necessary to induce earthquake slip, and therefore determine the limits of water injection operations appropriate for preventing unwanted induced seismicity. Important advances in technology have occurred in the nearly 50 years since the Rangely experiment. Rangely included no geodetic instrumentation and therefore could not assess the role of elasticity or creep in inducing earthquakes. Modern, digital and dense instrumentation could provide a much higher-resolution image of the earthquake locations that could address outstanding quandaries, such as the apparent location of the induced earthquakes kilometers away from the injection well.

\subsection{How do earthquakes nucleate?}

Laboratory-derived friction laws such as the rate-and-state equations imply that a small amount of aseismic creep should precede an earthquake. Such a precursory phase has long been sought in observational data, including foreshock sequences (e.g., Kato et al., 2012; Chen et al., 2017). More recently, geodetically measured slow slip events have been one of the more promising avenues for identifying an impending mainshock (e.g., Uchida et al., 2016). However, the scale of the precursory slip patch may be quite small, $10 \mathrm{~m}$ or less, and the ability to measure such a signal therefore likely depends on in situ measurements. In such a case, the larger-scale slow slip and foreshock sequences that are sometimes measured with surface instruments would be the result of more complex interactions between slip on the future rupture interface, the surrounding damage zone, potential fluid pressure changes, and heterogeneity of all of these properties along the fault (e.g., Savage et al., 2017). 


\subsection{What controls earthquake propagation and arrest?}

All earthquakes nucleate, but not all grow to large magnitudes. This implies that some earthquakes do not propagate significantly and arrest at small magnitudes instead. Rupture propagation is thought to be a function of the initial conditions in the source region, the constitutive laws that govern frictional sliding, and the geometrical properties of the host fault. The stress field and pore pressure distribution in and around a fault are heterogeneous, and the physical characteristics of faults such as roughness and damage zone characteristics are spatially variable. Constraining all of these parameters prior to an induced earthquake would be challenging, but near-field observations of the rupture tip zone would provide an unprecedented view of the underlying physical processes.

Because the answers to the three questions outlined at the SEISMS meeting are fundamental to predicting when and where large earthquakes will occur, the workshop participants were in agreement that an earthquake experiment by fluid injection should be pursued. The next order of business is to establish potential industry partners and have a more complete discussion of potential drilling targets. More immediately, the discussions begun at the SEISMS meeting are being continued at larger conferences, including the Continental Scientific Drilling Coordination Office (CSDCO) annual meeting and the 2017 American Geophysical Union (AGU) Fall Meeting.

Data availability. No data sets were used in this article.

Competing interests. The authors declare that they have no conflict of interest.

Acknowledgements. The authors gratefully acknowledge funding for the workshop, which was provided through the following grants: ICDP CU17-0069, USGS G17AP00037, and SCEC 16234.

Edited by: Thomas Wiersberg

Reviewed by: Sukanta Roy and Kazutoshi Immanishi

\section{References}

Ampuero, J. P. and Rubin, A. M.: Earthquake nucleation on rate and state faults-Aging and slip laws, J. Geophys. Res.-Sol. Ea., 113, B01302, https://doi.org/10.1029/2007JB005082, 2008.

Barbour, A., Norbeck, J. H., and Rubinstein, J. L.: The Effects of Varying Injection Rates in Osage County, Oklahoma, on the 2016 Mw 5.8 Pawnee Earthquake, Seismol. Res. Lett., 88, 1040-1053, https://doi.org/10.1785/0220170003, 2017.

Cappa, F., Guglielmi, Y., Gaffet, S., Lançon, H., and Lamarque, I.: Use of in situ fiber optic sensors to characterize highly heterogeneous elastic displacement fields in fractured rocks, Int. J. Rock Mech. Min., 43, 647-654, 2006.
Chen, X., Nakata, N., Pennington, C., Haffener, J., Chang, J. C., He, X., Zhan, Z., Ni, S., and Walter, J. I.: The Pawnee earthquake as a result of the interplay among injection, faults and foreshocks, Sci. Rep.-UK, 7, 4945, https://doi.org/10.1038/s41598017-04992-z, 2017.

Chiaraluce, L., Collettini, C., Cattaneo, M., and Monachesi, G.: The shallow boreholes at The AltotiBerina near fault Observatory (TABOO; northern Apennines of Italy), Sci. Dril., 17, 31 35, https://doi.org/10.5194/sd-17-31-2014, 2014.

Clerc, F., Harrington, R. M., Liu, Y., and Gu, Y. J.: Stress drop estimates and hypocenter relocations of induced seismicity near Crooked Lake, Alberta, Geophys. Res. Lett., 43, 6942-6951, https://doi.org/10.1002/2016GL069800, 2016.

Constantinou, A., Schmitt, D., Kofman, R., Kellett, R., Eccles, J., Lawton, D., Bertram, M., Hall, K., Townend, J., Savage, M., and Buske, S.: Comparison of fiber-optic sensor and borehole seismometer VSP surveys in a scientific borehole: DFDP-2b, Alpine Fault, New Zealand, in: SEG Technical Program Expanded Abstracts 2016 (pp. 5608-5612), Society of Exploration Geophysicists, 2016.

Cornet, F. H.: Seismic and aseismic motions generated by fluid injections, Geomechanics for Energy and the Environment, 5, 4254, 2016.

Deng, K., Liu, Y., and Harrington, R. M.: Poroelastic stress triggering of the December 2013 Crooked Lake, Alberta, induced seismicity sequence, Geophys. Res. Lett., 43, 8482-8491, 2016.

Derode, B., Guglielmi, Y., De Barros, L., and Cappa, F.: Seismic responses to fluid pressure perturbations in a slipping fault, Geophys. Res. Lett., 42, 3197-3203, 2015.

De Barros, L., Daniel, G., Guglielmi, Y., Rivet, D., Caron, H., Payre, X., Bergery, G., Henry, P., Castilla, R., Dick, P., and Barbieri, E.: Fault structure, stress, or pressure control of the seismicity in shale? Insights from a controlled experiment of fluid-induced fault reactivation, J. Geophys. Res.-Sol. Ea., 121, 4506-4522, 2016.

Dunham, E. M., Belanger, D., Cong, L., and Kozdon, J. E.: Earthquake ruptures with strongly rate-weakening friction and offfault plasticity, Part 2: Nonplanar faults, B. Seismol. Soc. Am., 101, 2308-2322, 2011.

Ellsworth, W. L.: Injection-induced earthquakes, Science, 341, 1225942, https://doi.org/10.1126/science.1225942, 2013.

Fulton, P. M., Brodsky, E. E., Kano, Y., Mori, J., Chester, F., Ishikawa, T., Harris, R. N., Lin, W., Eguchi, N., and Toczko, S.: Low coseismic friction on the Tohoku-Oki fault determined from temperature measurements, Science, 342, 1214-1217, 2013.

Goebel, T. H. W., Weingarten, M., Chen, X., Haffener, J., and Brodsky, E. E.: The 2016 Mw 5.1 Fairview, Oklahoma earthquakes: Evidence for long-range poroelastic triggering at $>40 \mathrm{~km}$ from fluid disposal wells, Earth Planet. Sc. Lett., 472, 50-61, 2017.

Guglielmi, Y., Cappa, F., Avouac, J. P., Henry, P., and Elsworth, D.: Seismicity triggered by fluid injection-induced aseismic slip, Science, 348, 1224-1226, 2015.

Hauksson, E., Goebel, T. H. W., Ampuero, J.-P., and Cochran, E.: A century of oil-field operations and earthquakes in the greater Los Angeles Basin, southern California, The Leading Edge, 34, 650-656, https://doi.org/10.1190/tle34060650.1, 2015.

Hennings, P., Allwardt, P., Paul, P., Zahm, C., Reid Jr., R., Alley, H., Kirschner, R., Lee, B., and Hough, E.: Relationship between fractures, fault zones, stress, and reservoir productivity in the 
Suban gas field, Sumatra, Indonesia, AAPG bulletin, 96, 753$772,2012$.

Huang, Y., Ellsworth, W. L., and Beroza, G. C.: Stress drops of induced and tectonic earthquakes in the central United States are indistinguishable, Science Advances, 3, e1700772, https://doi.org/10.1126/sciadv.1700772, 2017.

Ikeda, R.: Outline of the fault zone drilling project by NIED in the vicinity of the 1995 Hyogo-ken Nanbu earthquake, Japan, Island Arc, 10, 199-205, 2001.

Kato, A., Obara, K., Igarashi, T., Tsuruoka, H., Nakagawa, S., and Hirata, N.: Propagation of slow slip leading up to the 2011 Mw 9.0 Tohoku-Oki earthquake, Science, 335, 705-708, 2012.

Keranen, K., Weingarten, M., Abers, G. A., Bekins, B. A., and Ge, S.: Sharp increase in central Oklahoma seismicity since 2008 induced by massive wastewater injection, Science, 345, 448-451, https://doi.org/10.1126/science.1255802, 2014.

Li, H., Wang, H., Xu, Z., Si, J., Pei, J., Li, T., Huang, Y., Song, S. R., Kuo, L. W., Sun, Z., and Chevalier, M. L.: Characteristics of the fault-related rocks, fault zones and the principal slip zone in the Wenchuan Earthquake Fault Scientific Drilling Project Hole1 (WFSD-1), Tectonophysics, 584, 23-42, 2013.

Ma, K. F., Tanaka, H., Song, S. R., Wang, C. Y., Hung, J. H., Tsai, Y. B., Mori, J., Song, Y. F., Yeh, E. C., Soh, W., and Sone, H.: Slip zone and energetics of a large earthquake from the Taiwan Chelungpu-fault Drilling Project, Nature, 444, 473-476, 2006.

McGarr, A.: Maximum magnitude earthquakes induced by fluid injection, J. Geophys. Res.-Sol. Ea., 119, 1008-1019, https://doi.org/10.1002/2013JB010597, 2014.

McGuire, J. J., Boettcher, M. S., and Jordan, T. H.: Foreshock sequences and short-term earthquake predictability on East Pacific Rise transform faults, Nature, 434, 457-461, 2005.

Raleigh, C. B., Healy, J. H., and Bredehoeft, J. D.: An experiment in earthquake control at Rangely, Colorado, Science, 191, 1230 1237, 1976.

Rice, J. R.: Spatio-temporal complexity of slip on a fault, J. Geophys. Res.-Sol. Ea., 98, 9885-9907, 1993.
Rivet, D., De Barros, L., Guglielmi, Y., Cappa, F., Castilla, R., and Henry, P.: Seismic velocity changes associated with aseismic deformations of a fault stimulated by fluid injection, Geophys. Res. Lett., 43, 9563-9572, https://doi.org/10.1002/2016GL070410, 2016.

Savage, H. M., Keranen, K. M., Schaff, D. P., and Dieck, C.: Potential precursory signals in damage zone foreshocks, Geophys. Res. Lett., 44, 5411-5417, 2017.

Scholz, C. H.: Earthquakes and friction laws, Nature, 391, 37-42, 1998.

Segall, P. and Lu, S.: Injection-induced seismicity: Poroelastic and earthquake nucleation effects, J. Geophys. Res.-Sol. Ea., 120, 5082-5103, https://doi.org/10.1002/2015JB012060, 2015.

Sumy, D. F., Neighbors, C. J., Cochran, E. S., and Keranen, K. M.: Low stress drops observed for aftershocks of the $2011 \mathrm{Mw} 5.7$ Prague, Oklahoma, earthquake, J. Geophys. Res.-Sol. Ea., 122, 3813-3834, 2017.

Uchida, N., Iinuma, T., Nadeau, R. M., Bürgmann, R., and Hino, R.: Periodic slow slip triggers megathrust zone earthquakes in northeastern Japan, Science, 351, 488-492, 2016.

van der Elst, N. J., Page, M. T., Weiser, D. A., Goebel, T. H. W., and Hosseini, S. M.: Induced earthquake magnitudes are as large as (statistically) expected, J. Geophys. Res.-Sol. Ea., 121, 45754590, https://doi.org/10.1002/2016JB012818, 2016.

Viesca, R. C. and Garagash, D. I.: Ubiquitous weakening of faults due to thermal pressurization, Nat. Geosci., 8, 875-879, 2015.

Yabe, Y., Nakatani, M., Naoi, M., Philipp, J., Janssen, C., Watanabe, T., Katsura, T., Kawakata, H., Georg, D., and Ogasawara, H.: Nucleation process of an M2 earthquake in a deep gold mine in South Africa inferred from on-fault foreshock activity, J. Geophys. Res.-Sol. Ea., 120, 5574-5594, 2015.

Yeck, W. L., Weingarten, M., Benz, H. M., McNamara, D. E., Bergman, E. A., Hermann, R. B., Rubinstein, J. L., and Earle, P. S.: Far-field pressurization likely caused on of the largest injection induced earthquakes by reactivating a large preexisting basement fault structure, Geophys. Res. Lett., 43, 1-10, 2016. 